\title{
Analysis of Team Construction of Sport Management Talents in the "Twelfth Five-year" Plan
}

\author{
Yangang Liao ${ }^{1, a, *}$ \\ ${ }^{1}$ Department of Physical Education, Capital University of \\ Economics and Business, Beijing, China \\ aliaoyangang@sina.com
}

\author{
Hengchan Yin ${ }^{2, b}$ \\ ${ }^{2}$ College of P.E and Sports, Beijing Normal University, \\ Beijing, China \\ byinhengchan@bnu.edu.cn \\ *Corresponding author
}

\begin{abstract}
Sports management talents play an important supporting role in promoting sport cause, achieving new development so as to construct a world sports power during the“Twelfth Five-year"period. The article analyzes the overall situation of current sport management talents construction, discusses the existing problems and proposes some suggestions on its development, in the hope of making contribution to personnel-training and policy-making as reference for some relevant departments in our country.
\end{abstract}

Keywords- “Twelfth Five-year" Plan, Sports Management Talents, Team Construction;

\section{INTRODUCTION}

For a long time, the Central Party Committee, the State Council attached great importance to talent-related work, implementing the strategy of "talents-empowing-nation". Comrade $\mathrm{Hu}$ Jintao once emphasized: "talents-related working is the key issue to the development of the Party and national work." The 16th National Congress Party further developed the guideline--- "respecting knowledge and respecting talents," into "respecting work, respecting knowledge, respecting talents, and respecting creation", broadening the vision of talents related work. Sports Minister Liu Peng, said at the meeting of Nation's Sports Secretary in 2005, "Talent is the foundation of sports" development and perfecting. We should vigorously develop an outstanding sports talent team in China and ensure a strong and broad intellectual support for sports' comprehensive, coordinated and sustainable development. ”

Sports management talents are those who are engaged at all levels of sports administration and organizations, including sports executive public servants, sports management personnel and other sports related personnel administration. Sports management talent team include sports executive units, sports institutions, and even sports enterprise, sports news, sports organizations, including almost all of the sports management. The quality of the team has become a key ingredient in the development of national sports. In other words, the number and level of national sports talent determines the national sports situation. We need a lot of sports management talents in the construction of a world sports power. The construction of sports management talents will directly affect the building of a comprehensive and sustainable sports cause

"Twelfth Five-Year" period, the golden five years to achieve scientific and harmonious development of our society, is also an important phase to promote sport cause, achieve new development and breakthough so as to build a world sports power. "Twelfth Five-year" plan clearly pointed out that we should thoroughly implement talents strategy, make greater efforts to talents training in some key areas, perfect the incentive policy contributing to the growth of various talents and facilitating the building of a sports talents team with sufficient quantity, good quality, wide range and rational organization.

The development, training and management of sports management talents have significant influence on sports' long-term development. The starting point of all this work is to fully understand the importance of constructing sports management personnel to the social and economic development in China. The main purpose of this paper is to understand the current situation of our national sports management talents, reveal the existing problems, explore strategies for development. We hope to make contribution to personnel-training and policy-making as reference for some relevant departments in our country and provide reasonable proposals for further development

\section{ANALysis OF THE TEAM OF SPORTS MANAGEMENT TALENTS}

From the foundation of New China to now, the working system and mechanism of sports management talents is more perfect, the team making up of party and government leading cadres in the national sports departments at various levels, the teams constituted by civil servants, the technical professionals keep increasing and growing in its quantity and quality. The structure is more rational and the overall power is keeping strengthening. Younger, better educated complex talents surge out. In 1980s, the sports system is based on elementary educated personnel, with lower degrees and less college-educated talents. By constantly promoting the personnel system reform, increasing the investment in educational training and etc, in 2005, the National Sports Talent Resources Survey data show that there is a total of 62,473 sports management professionals in our country, accounting for $45.5 \%$ of the total sport 
talents. The overall cultural level of sports management personnel is keeping improving, talents with Ph.D. or MA are becoming more and more gradually, nearly $80 \%$ of the staff have Bachelor's degree or more. Compared with the less than $50 \%$ counterpart of the $1980 \mathrm{~s}$, it is a great breakthrough in quality. Besides, the overall age structure of the sports management talents is rather rational, among which, the 56-odd-year-olds take up only 5\%, the sports management talents is mainly backboned by medium youth team (65\%). On the professional structure, the talent major in athletics occupies the predominant position in the sports management, embodying the successful practice of the guiding ideology of "specialization". The proportion of Management, Law, Economics specialties is further increased, showing evidence of the establishing and perfecting of socialist market-driven economic system being in accordance with trend of accelerating social legislation in China, which has a positive role in smoothly progressing the reform and innovation of sports management system, accelerating the building process of sports and sports industry. And the success of the Beijing Olympic Games cultivated a large number of senior sports management talents with knowledge of management, sports as well as management business philosophy

In fact, the sports management talent team's overall strength is still relatively weak, with great margin compared with other professional talents construction. According to relevant data, related sports management professionals are more concerned with competitive sports, unable to keep up with the rapid and healthy development of the sports with growing prosperity either in quantity or quality. In talents team, the phenomena such as somewhat talent level hierarchy, lower educational degree and homogeneous professional background are not rare. Athletic talents take up a larger proportion of sports talents, while talents on management, economics, law and other professional categories are obviously insufficient. Complex, innovative sports management talents and young reserve are low in quantity, without any effective talent chain; The building of talent team needs to be improved, as there is still a gap in educational degree compared with other industries. There is a lack of complex and high-level talents who have an eclectic knowledge of sports economy, sports marketing, public relation, sports organizing and planning, foreign language and so on. Furthermore, there is a shortage of management staff to hold grand international competition, who should be blessed with excellent operational capacity, overall quality and knowledge background. In a word, as for the objective of building a "sports power", we still have a long way to go and place much emphasis to the issues mentioned above in future work.

\section{Proposals on Developing Sports Management TALENTS TEAM IN THE “TWELFTH FIVE-YEAR”}

It is possible that, the development of Chinese sports management talents will face many opportunities and challenges during the period of the "Twelfth Five-year" to achieve the development strategy of "talents-strenthening-sports", we must solve the existing problems and contradictions so as to achieve the comprehensive, coordinated and sustainable development in sports. Therefore, we proposed some suggestions:

\section{A. Deepening reform and strengthening innovation to} create a favorable environment for talent development

We should make market system fully play its basic role in the allocation of talent resources and perfect the market management system in sports management talents; We must keep improving the legislation system of talent management, cultivate talent market system, establish competitive rules of sports talent resources and adjust the development direction of talent resources by means of policy and economic lever. Furthermore, to maximally optimize the hard and soft environment of sports industry management personnel, we should further optimize the environment of talent management, building the good atmosphere of "respecting knowledge, respecting talents" and developing a series of active personnel policy, reforming the existing personnel system and the operating talents mechanism, establishing a mechanism with good competition, reasonable incentives, and highly efficient coordination through the development and utilization of talent resources.

B. Cultivating a sports mamagement talents team with sufficient quantity, rational structure, and outstanding quality to promote team's coordination and development.

We must attach great importance to the strategic reserve of leaders, reinforce the cultivating and selecting of young leaders. We should improve the overall quality of sports management talents, adhering to attract the elite endowed with ideals, beliefs, business ability, team spirit into our groups. We should vigorously strengthen the team construction at various levels, including talents on sports industry management, international sports organization, sports foreign affairs, sports promotion, law and other fields. We should cultivate a large number of high-quality, international, interdisciplinary talents, adjust and optimize the team structure of sports management personnel, and promote comprehensive, coordinated development of sports talents team

\section{Carrying out large-scale education and training to vigorously promote the overall quality of talents}

To cultivate a multitude of high-quality talents of sports management, we must strengthen the talents' cultural educating, improving their ideological, scientific and cultural qualities, We should carry our educational training on large scale, promote and perfect the building of educational training system with the characteristics of Chinese Physical education and integrate talents selection and evaluation with their educational training to perfect the training management system and incentive-binding mechanism. We should increase education and training funding, broaden the financing channels and strengthen funds management. 
D. Strengthening the communication and cooperation of sports management personnel to promote the highly efficient integration of talent resources.

We should improve the flow mechanism of talent resources encouraging the rational and orderly flow of sports management professionals, developing talent resources to the full. The coordination of the overall human resources structure and efficiency could be realized and improved via talent flow between regions, sectors, levels and positions. We should establish a national market mechanism for introducing sports talents and make full use of external human resources market, widely attract talented professionals, promote the efficient integration of human resources. We should intensify the "inviting in" and "sending out" effort, select the backbone of sports organizations and send them out to learn advanced training, management theory and experience abroad, and invite foreign experts and scholars to give long-term or short-term lectures and coaching, facilitate academic and information exchanges. In addition, we need to develop policies appropriately tilted in favor of, the central and western regions in funding, site construction, personnel training, technology efforts, competition organization and so on, give them proper care and benefits, support their development of human resources of sports management and reinforce the building of grass-root's sport management talent team and facilitate sports talents' regional flow and development

\section{CONCLUSION}

4.1 The team building of sport management talents plays an important supporting role in building a world sports power. The team of sports management talents has been expanding steadily, and its comprehensive strength is keeping rising. However, the problem of overall quality being not high, lack of balance in development and etc need to be solved with much more emphasis by us in future work.

4.2 During the the "Twelfth Five-year"period, the team construction of sports management personnel need to continuously strengthen their self-discpline, deepening reform and innovation, and creating a good employment environment. We should speed up the exploitation and utilization of all kinds of sports human resources, promote efficient integration of human resources and provide powerful talent support for sustainable, comprehensive and coordicated development of sports.

\section{REFERENCES}

[1] Peng Liu,China Sports in three decades of reform and opening up, People's Sports Publishing House,Beijing,2008.

[2] JianMei Zhou, Regional Economic Development and Sports Talent, Beijing Sport University Press,Beijing,2007.

[3] Yan,Zhou Tang Weina, Sports Talent Study,Southwest China Normal University Press,Chongqing,2006

[4] Yangang Liao, The development of sports talents and achievementsin 60 Years of New China. The frontiers of chinese talents(NO.5), Social Sciences Academic Press, 2010.

[5] Chengang Pan; Talents development report of China(NO.5), Social Sciences Academic Press, beijing ,2008.

[6] China Human Resources Development Strategy of Sport, State Sports General Administration, "Eleventh Five-Year Plan" research,2007 